\title{
Morphology of the Physiological Apical Foramen of Maxillary Premolars
}

\author{
Morfología del Foramen Apical de Premolares Maxilares
}

\author{
Abarca, Jaime ${ }^{1,2}$; Zaror, Carlos ${ }^{1,3}$; Contreras, Wendy ${ }^{4}$; Jadue, Sofia ${ }^{4}$; \\ Olguin, Carlos ${ }^{2,5}$; Steinfort, Karin ${ }^{2}$ \& Monardes, Hector ${ }^{2,5}$
}

ABARCA, J.; ZAROR, C.; CONTRERAS, W.; JADUE, S.; OLGUIN, C.; STEINFORT, K. \& MONARDES, H. Morphology of the physiological apical foramen of maxillary premolars. Int. J. Morphol., 36(1):164-168, 2018.

SUMMARY: The purpose of this study was to determine the shape and diameter of the physiological foramen in maxillary premolars of a Chilean population. The sample consisted of 125 extracted maxillary premolars, in which the apical three to five millimeters were cut and observed under magnification of 40x, photographed (Motic Cam), and analyzed using Motic Images Plus 2.0 ML in order to obtain measurements of the minor and major diameter of each physiological foramen. The average minor and major diameter in maxillary premolars was 0.270 and $0.413 \mathrm{~mm}$, respectively. In terms of shape, $72.19 \%$ had oval shaped physiological foramen; $18.93 \%$ were irregularly shaped and $8.88 \%$ were round. Oval and irregular canals are significantly more difficult to shape and require special attention in order to obtain a thoroughly disinfected root canal system.

KEY WORDS: Apical constriction; Apical diameter; Maxillary premolars; Physiological foramen; Root apex.

\section{INTRODUCTION}

Thorough knowledge of the internal root anatomy is of the utmost importance for the success of root canal therapy. (Vertucci, 2005; Wu et al., 2017) An especially critical part of the cleaning and shaping procedures rests on the knowledge of the characteristics of the apical terminus of the preparation, that is the physiological foramen or apical constriction, in order to determine the final size of the preparation (Marroquín et al., 2004) and the type of instrument or instrumentation technique, that will be required in order to obtain a properly shaped canal (Wu et al., 2000). However, there is little evidence regarding the anatomy of the physiological foramen of maxillary premolars, even though these teeth are thought to have one of the most complex apical anatomies (Morfis et al., 1994; Vertucci).

It is not possible to clinically determine the precise diameter of the physiological foramen in all its amplitude. Among the currently used methods to study its specific morphology, micro-CT scans allow a three-dimensional evaluation of its shape, position and size (Meder-Cowherd et al., 2011; Ordinola-Zapata et al., 2013; Wolf et al., 2016). This is a noninvasive method that allows an accurate analysis of the number of root canals present and their particular configurations (Briceño-Marroquin et al., 2015); however, they are difficult to access. This disadvantage is overcome by the use of a microscopic technique that allows observation under different magnifications of teeth ex vivo, either by a direct visualization of the apex, or by analyzing a sagittal or cross-sectional cut in order to visualize the entire length of the apical anatomy. This is a simple and reproducible method to study apical anatomy (Martos et al., 2009; Abarca et al., 2014).

In the era of mechanical instrumentation, a current goal is to achieve complete canal conformation with the least number of files possible (De-Deus et al., 2015). Nonetheless, in many cases, this leads to a choice that is based on practicality and not on dental anatomy. In order to determine the last file or master apical file and therefore, the system that should be used in a particular case, it is

\footnotetext{
${ }^{1}$ Faculty of Dentistry, Universidad San Sebastián, Puerto Montt, Chile.

${ }^{2}$ Endodontics Graduate Program, Faculty of Dentistry, Universidad San Sebastián, Santiago, Chile.

${ }^{3}$ Center for Research in Epidemiology Economics and Oral Public Health (CIEESPO), Faculty of Dentistry, Universidad de La Frontera, Temuco, Chile.

${ }^{4}$ Endodontics Private Practice, Chile.

${ }^{5}$ Faculty of Dentistry, Universidad San Sebastián, Santiago, Chile.
} 
very important to know the diameter of the foramen we intend to shape. This quantitative knowledge of apical anatomy would be of assistance in the decision- making process, regarding file systems and specific file sizes (Abarca et al.; Briseño-Marroquín et al., 2015).

Despite the fact that a few apical morphology studies in Indian, Turkish and European populations (Marroquín et al.; Arora \& Tewari, 2009; Ayranci et al., 2013; ElAyouti et al., 2014) have shown a great complexity and a relatively high incidence of oval physiological foramens (between 40 and $89 \%$ ) (Marroquín et al.; Arora \& Tewari; Ayranci et al.; Arias et al., 2017), there are no studies regarding the apical anatomy of maxillary premolars in a Chilean or other South American population. The purpose of this study was to determine the most common shape and diameter of the physiological foramen in roots of extracted maxillary premolars of a Chilean population, attempting to shed further light in in terms of the measures that would be necessary to properly prepare and disinfect this tooth type in this particular population.

\section{MATERIAL AND METHOD}

A descriptive ex vivo study was conducted using 150 maxillary premolars that had been recently extracted from a sample population of the Chilean Central Zone. The reasons for extraction were periodontal, pulpal, orthodontic or prosthetic. Maxillary first and second premolars that had complete root development were included. Teeth with previously initiated therapy, endodontically treated or with apical resorption, were excluded from the study.

Sample Preparation. After the extraction procedure, the teeth were washed with running water, debrided with a Gracey Curette No 5/6 (Hu-Friedy®) to remove remaining periodontal tissue and calculus, and deposited in a flask filled with saline solution. This flask was then labeled with the tooth type and patient age and sex. The roots were cut in a cross-sectional manner to a distance three to five millimeters from the anatomical apex with a diamond disk with abundant refrigeration (saline solution). A total of 169 sections were obtained. These were then submerged in $5 \%$ sodium hypochlorite for 24 hours to disinfect the samples and to remove organic residues. Finally, they were submerged in Hydrogen Peroxide for an hour, washed in running water and dried with gauze and pressured air. In the case of persistence of organic tissue in the apical foramen, a K 06 file (Dentsply Sirona $\left.{ }^{\circledR}\right)$ was used to remove it.
Photographs of each sample (Motic Cam) were taken under 40x magnification, and they were analyzed using Motic Images Plus 2.0 ML, measuring the minor and major diameter of each physiological foramen. Measurements were made in millimeters and adjusted to three digits after the decimal, as can be observed in Figure 1. A foramen was considered the physiological foramen when it measured at least $0.10 \mathrm{~mm}$. When it measured less than this, it was considered to be an accessory foramina (Abarca et al.).

Foraminal shape was determined using the previous measurements in the following manner: round shape presented a difference of less than $0.02 \mathrm{~mm}$ between the minor and major diameter; oval shape presented a difference of more than 0.02 $\mathrm{mm}$, and irregular cases had triangular, kidney-like or asymmetrical shapes (Marroquín et al.) (Fig. 1).

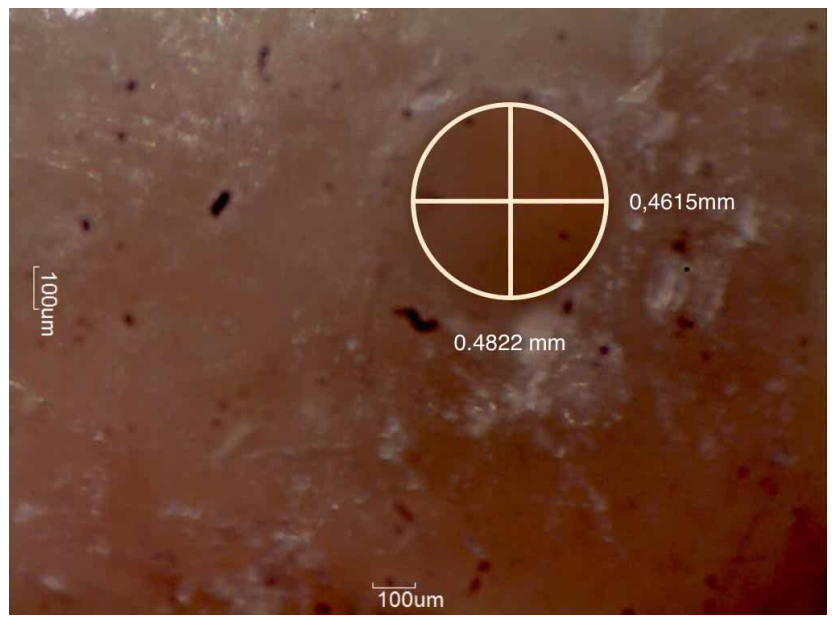

Fig. 1. Measurement of the physiological foramen.

Calibration. Prior to performing the photographical analysis, the observers underwent theoretical and practical training. Specific parameters were established for the measurement method. Each observer evaluated fifteen random samples in different rooms, maintaining time, light and screen resolution conditions. Ten days later, the entire process was repeated. Intra and inter-examiner concordance was calculated through the Intraclass Correlation Coefficient (ICC) using EPIDAT 4.0, obtaining an intra and interexaminer ICC $=0.999$, indicating high concordance (Prieto et al., 1998).

Statistical Analysis. A descriptive and inferential analysis was performed using STATA 12 Program (Stata Corp LP, USA $\left.{ }^{\circledR}\right)$. Chi-square and ANOVA analyses were applied. For both diameter and shape, the significance level was 0.05 . The results were expressed through tables and graphics that show distribution frequency, a summary of the measurements and variable associations. 


\section{RESULTS}

Of the 150 maxillary premolars, twenty-five teeth were discarded because they presented either radicular fracture or a non-observable physiological foramen. The analyzed sample contained 125 maxillary premolars of patients with an average age of 31.4 years (SD 14.3y), and $64.5 \%$ were female patients. The sample included 80 foramens of first premolars and 89 foramens of second premolars; 44 were buccal, 47 palatal and 78 were from single-rooted teeth.

The average minor and major diameters were 0.270 and $0.413 \mathrm{~mm}$, respectively. Table I shows the amount of roots per premolar type (first or second premolar) and the average diameter of each foramen. The results separated by tooth type and number of roots were as follows: for first premolars, single-rooted ones had an average minor and major diameter of 0.288 and $0.345 \mathrm{~mm}$, respectively, 0.262 and $0.360 \mathrm{~mm}$ for palatal roots and 0.247 and $0.396 \mathrm{~mm}$ for buccal roots; for second premolars the average diameters were 0.338 and $0.544 \mathrm{~mm}$ for single rooted ones, 0.258 and 0.409 $\mathrm{mm}$ for palatal roots and 0.229 and $0.336 \mathrm{~mm}$ for buccal roots.

The most common shape for all maxillary premolars was oval $(72.19 \%)$, followed by irregularly shaped $(18.93 \%)$ and round shaped $(8.88 \%)$. Ovalshaped foramen represented $72 \%$ of the sample for first premolars and $73 \%$ of the sample for second premolars). Figure 2 shows the frequency of the shape of each root and Figure 3 the different types of foramen.

There were no statistical differences in shape $(p>0.05)$ in relation to sex, age or number of roots. Regarding diameter, there were no statistical differences $(p>0.05)$ in relation to age or sex. Nonetheless, there was a difference in relation to the number of roots $(\mathrm{p}<0.05)$ : the diameter was smaller in premolars with two roots in comparison to single rooted ones.

\section{Shape of the Physiological Foramen}

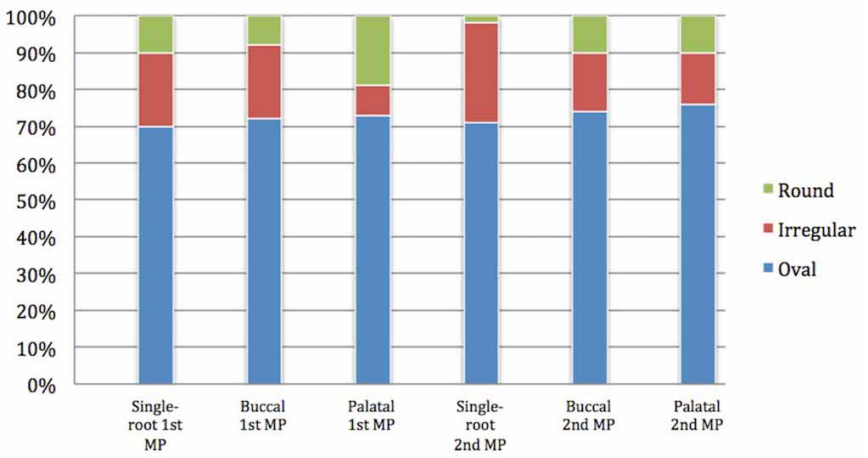

Fig. 2. Distribution by percentage of the foraminal shapes.

\section{DISCUSSION}

To the best of our knowledge, there are no studies that measure physiological apical foramen in premolars exclusively. Most studies focus on maxillary or mandibular molars, even though maxillary premolars are considered to possess the most complex apical anatomy of human dentition, according to Vertucci and Morfis et al.

The knowledge of the expected diameters of the physiological foramen should be of assistance to clinicians in order to obtain a proper apical disinfection. This should be accomplished without over-enlarging this constriction, according to Schilder's principles of cleaning and shaping (Schilder, 1974; Buchanan, 2000); average values can help in this decision-making process, although this physiological foramen should be gauged in every clinical situation in order to determine the final instrument to be used, at working length (Schilder; Wu et al., 2000; Marroquín et al.; Vanni et al., 2005). As this assessment is eventually made by tactile sensation, the information about average sizes of specific physiological foramen helps in making a more informed decision (Schilder).

The average minor diameter observed was of $0.270 \mathrm{~mm}$ and $0.413 \mathrm{~mm}$ for the major diameter, which are higher values than what was observed by Morfis et al. (0.210 mm), Ayranci (0.161 and 0.302 $\mathrm{mm}$ for single-rooted first premolars and 0.168 and $0.259 \mathrm{~mm}$ for second premolars) and smaller than the results of Arora (average major diameter of $0.24 \mathrm{~mm}$ for first premolars and $0.254 \mathrm{~mm}$ for

Table I. Central tendency measures of the major and minor diameter of the physiological foramen of maxillary premolars (MP).

\begin{tabular}{|c|c|c|c|c|c|c|c|c|c|c|c|c|}
\hline \multirow{2}{*}{$\begin{array}{l}\text { Root } \\
\mathrm{P}\end{array}$} & \multicolumn{2}{|c|}{$\begin{array}{c}\text { Single-root 1st MP } \\
n=30\end{array}$} & \multicolumn{2}{|c|}{$\begin{array}{c}\text { Buccal 1st MP } \\
n=25\end{array}$} & \multicolumn{2}{|c|}{$\begin{array}{c}\text { Palatal 1st MP } \\
n=26\end{array}$} & \multicolumn{2}{|c|}{$\begin{array}{l}\text { Single-root 2nd MP } \\
n=48\end{array}$} & \multicolumn{2}{|c|}{$\begin{array}{c}\text { Buccal 2nd MP } \\
\mathrm{n}=19\end{array}$} & \multicolumn{2}{|c|}{$\begin{array}{c}\text { Palatal 2nd MP } \\
n=21\end{array}$} \\
\hline & Major & Minor & Major & Minor & Major & Minor & Major & Minor & Major & Minor & Major & Minor \\
\hline Minimum & 0.131 & 0.102 & 0.134 & 0.100 & 0.110 & 0.103 & 0.1711 & 0.131 & 169 & 0.118 & 0.139 & 0.100 \\
\hline Maximum & 1.764 & 0.510 & 1.278 & 0.653 & 0.892 & 0.529 & 1.1040 .544 & 0.689 & 0.646 & 0.357 & 0.919 & 0.626 \\
\hline Mean & 0.435 & 0.288 & 0.326 & 0.247 & 0.360 & 0.262 & 0.544 & 0.338 & 0.336 & 0.229 & 0.409 & 0.258 \\
\hline SD & 0.296 & 0.087 & 0.267 & 0.133 & 0.174 & 0.102 & 0.234 & 0.151 & 0.119 & 0.067 & 0.206 & 0.121 \\
\hline
\end{tabular}




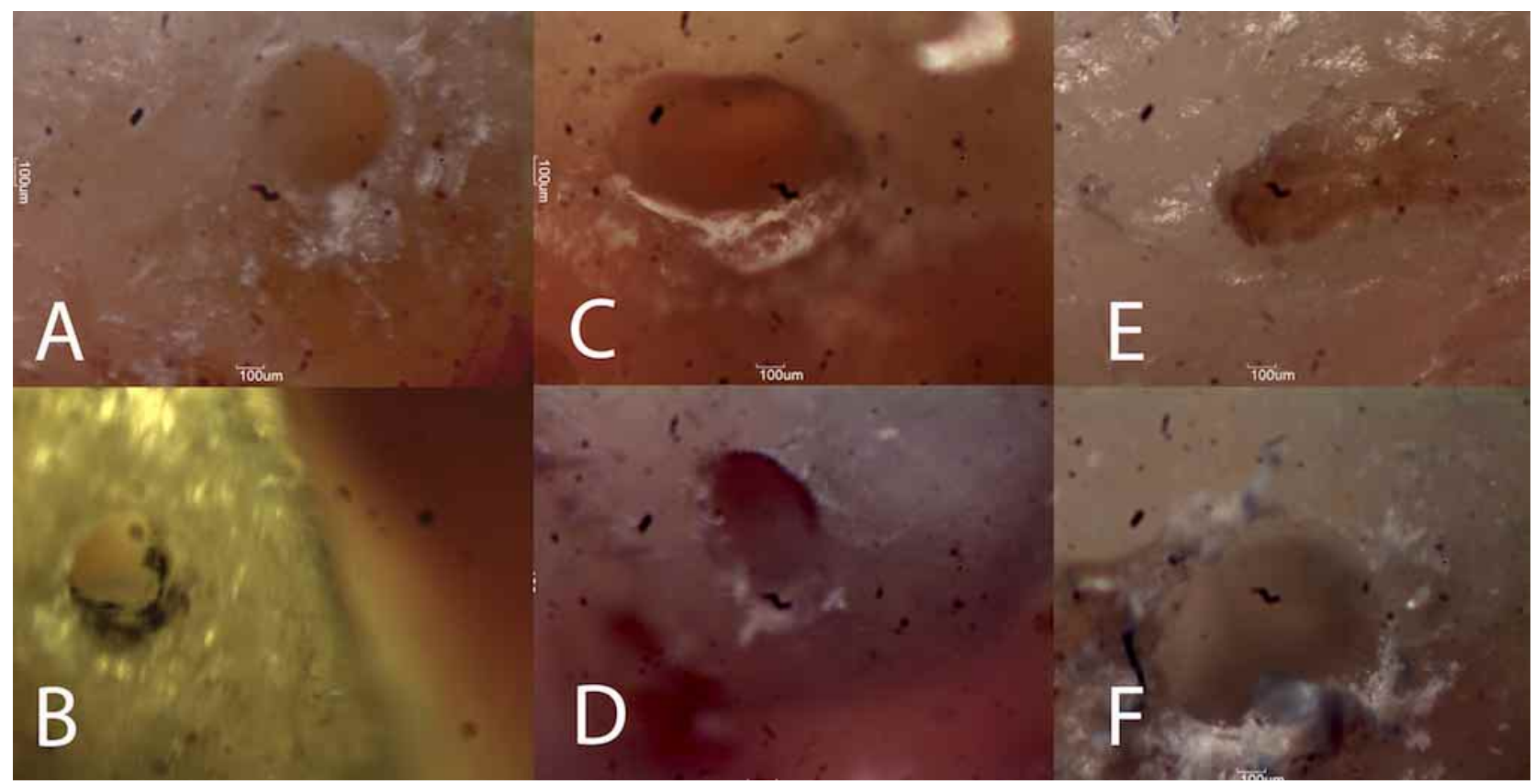

Fig. 3. Different shapes of the Physiological Foramen. Shape of the physiological foramen, A and B = round; C and D = oval; E and $\mathrm{F}=$ irregular.

second premolars) (Morfis et al.; Arora \& Tewari; Ayranci et al.). These differences may be due to sample heterogeneity, because the sample in these studies contained different tooth types and also because of ethnic differences (Marroquín $e t$ al.; Ahmad \& Alenezi, 2016; Wu et al., 2017).

The results show that the most common shape of maxillary premolars physiological apical foramen was oval ( $72.19 \%$ on average), which is similar to what was observed In other studies (between 67 and $70 \%$ ) (Marroquín et al.; Arora \& Tewari; Ayranci et al.). This calls special attention to the apical shaping of the canal, given that rotary instruments may tend to leave round preparations, which could lead to an inadequate preparation of this particularly delicate and critical area of root canal treatment (Schilder; Arias et al.). On the other hand, an attempt to over-enlarge oval canals, transforming them into round ones, may produce periodontal inflammation and eventually lead to treatment failure (Schilder; Wu et al., 2000; Marroquín et al., 2004). The question remains as to whether it would be better to enlarge the foramen to its major diameter, and possibly damage periodontal fibers or to gauge and work the foramen to its minor diameter and leave untreated walls. The effect this would have on treatment success also remains to be studied. In relation to the results of this study, this would be translatable to using a 25 size file or a 40 size file to finish the apical preparation of maxillary premolars. Further evidence is also required of the proper apical size preparation in order to obtain root canal treatment success (Silva et al., 2016).
In terms of disinfection, oval canals are significantly more difficult to properly clean and shape; therefore, measures should be taken not only in relation to preparation size, but also in the irrigation and activation methods that are used to obtain successful clinical results (Aminoshariae $\&$ Kulild, 2015).

These results are also useful due to the fact that the major diameter in most cases was in the bucco-palatal direction. Thus, this implies that meticulous analysis of radiographs would not be of assistance in order to obtain an idea of the apical diameter, since this direction is not visible in conventional radiographs (Alves et al., 2011).

Furthermore, it was observed that the sample showed great heterogeneity, which would further prove the highly variable and complex anatomy that maxillary premolars possess. This could be one of the causes of failure, in cases that appear radiographically well executed (Vertucci; Martos et al., 2009, 2010).

Suggestions for further investigations would be to improve sample collection, by adding criteria such as the presence of apical pathology, occlusal trauma or severe chronic periodontitis, which may have an altering effect on apical foramen diameter. Other studies on the same population, perhaps using other techniques, would be useful in order to compare and further analyze the obtained results. 
CONCLUSIONS. The results of this study show that the average size of the physiological apical foramen of maxillary premolars is $0.270 \mathrm{~mm}$ for the minor diameter and 0.413 for the major diameter. The most common shape for this foramen is oval. Both these facts may have an effect on the choice of shaping instrument size and type in order to produce a proper apical preparation.

ACKNOWLEDGEMENTS. This research did not receive any specific grant from funding agencies in the public, commercial, or non-profit sectors.

ABARCA, J.; ZAROR, C.; CONTRERAS, W.; JADUE, S.; OLGUIN, C.; STEINFORT, K. \& MONARDES, H. Morfología del foramen apical de premolares maxilares. Int. J. Morphol., 36(1):164$168,2018$.

RESUMEN: El objetivo del estudio fue determinar la forma y el diámetro del foramen fisiológico de premolares maxilares en una población Chilena. La muestra consistió en 125 premolares maxilares extraídos, a los que se cortó de 3 a 5 milímetros apicales, fueron observados bajo magnificación de 40x, fotografiado (Motic Cam) y analizados utilizando Motic Images Plus 2.0 ML para obtener las mediciones de el diámetro menor y mayor de cada foramen fisiológico. El promedio del diámetro menor y mayor en premolares maxilares fue de 0,270 y $0,413 \mathrm{~mm}$ respectivamente. En cuanto a la forma $72,19 \%$ tenía el foramen fisiológico de forma oval; $18,93 \%$ tenía forma irregular y $8,88 \%$ fue redondo. Canales ovales e irregulares son significativamente más difíciles de conformar y requieren especial atención para obtener una adecuada desinfección del sistema de canales radiculares

PALABRAS CLAVE: Constricción apical; Diámetro apical; Premolares Maxilares; Foramen fisiológico; Ápice radicular.

\section{REFERENCES}

Abarca, J.; Zaror, C.; Monardes, H.; Hermosilla, V.; Muñoz, C. \& Cantin, M. Morphology of the physiological apical foramen in maxillary and mandibular first molars. Int. J. Morphol., 32(2):671-7, 2014.

Ahmad, I. A. \& Alenezi, M. A. Root and root canal morphology of maxillary first premolars: A literature review and clinical considerations. J. Endod., 42(6):861-72, 2016.

Alves, F. R.; Almeida, B. M.; Neves, M. A.; Moreno, J. O.; Rôças, I. N. \& Siqueira, J. F. Jr. Disinfecting oval-shaped root canals: effectiveness of different supplementary approaches. J. Endod., 37(4):496-501, 2011

Aminoshariae, A. \& Kulild, J. C. Master apical file size - smaller or larger: a systematic review of healing outcomes. Int. Endod. J., 48(7):639-47, 2015.

Arias, A.; Paqué, F.; Shyn, S.; Murphy, S. \& Peters, O. A. Effect of canal preparation with TRUShape and Vortex rotary instruments on three-dimensional geometry of oval root canals. Aust. Endod. J., 2017, doi: 10.1111/ aej.12201 [Epub ahead of print]

Arora, S. \& Tewari, S. The morphology of the apical foramen in posterior teeth in a North Indian population. Int. Endod. J., 42(10):930-9, 2009.

Ayranci, L. B.; Yeter, K. Y.; Arslan, H. \& Kseoglu, M. Morphology of apical foramen in permanent molars and premolars in a Turkish population. Acta Odontol. Scand., 71(5):1043-9, 2013.

Briseño-Marroquín, B.; Paqué, F.; Maier, K.; Willershausen, B. \& Wolf, T. G. Root canal morphology and configuration of 179 maxillary first molars by means of micro-computed tomography: An ex vivo study. J. Endod., 41(12):2008-13, 2015.

Buchanan, L. S. The standardized-taper root canal preparation--Part 1. Concepts for variably tapered shaping instruments. Int. Endod. J., 33(6):516-29, 2000.
De-Deus, G.; Belladonna, F. G.; Silva, E. J. N. L.; Marins, J. R.; Souza, E. M.; Perez, R.; Lopes, R. T.; Versiani, M. A.; Paciornik, S. \& Neves, A. de A. Micro-CT evaluation of non-instrumented canal areas with different enlargements performed by NiTi Systems. Braz. Dent. J., 26(6):624-9, 2015.

ElAyouti, A.; Hülber, J. M.; Judenhofer, M. S.; Connert, T.; Mannheim, J. G.; Löst, C.; Pichler, B. J. \& von Ohle, C. Apical constriction: location and dimensions in molars-a micro-computed tomography study. J. Endod., 40(8):1095-9, 2014.

Marroquín, B. B.; El-Sayed, M. A. \& Willershausen-Zönnchen, B. Morphology of the physiological foramen: I. Maxillary and mandibular molars. J. Endod., 30(5):321-8, 2004

Martos, J.; Ferrer-Luque, C. M.; González-Rodríguez, M. P. \& Castro, L. A. Topographical evaluation of the major apical foramen in permanent human teeth. Int. Endod. J., 42:329-34, 2009.

Martos, J.; Lubian, C.; Silveira, L. F.; Suita de Castro, L. A. \& Ferrer Luque, C. M. Morphologic analysis of the root apex in human teeth. J. Endod., 36(4):664-7, 2010

Meder-Cowherd, L.; Williamson, A. E.; Johnson, W. T.; Vasilescu, D.; Walton, R. \& Qian, F. Apical morphology of the palatal roots of maxillary molars by using micro-computed tomography. J. Endod., 37(8):1162-5, 2011.

Morfis, A.; Sylaras, S. N.; Georgopoulou, M.; Kernani, M. \& Prountzos, F. Study of the apices of human permanent teeth with the use of a scanning electron microscope. Oral Surg. Oral Med. Oral Pathol., 77(2):172-6, 1994.

Ordinola-Zapata, R.; Bramante, C. M.; Villas-Boas, M. H.; Cavenago, B. C.; Duarte, M. H. \& Versiani, M. A. Morphologic micro-computed tomography analysis of mandibular premolars with three root canals. J. Endod., 39(9):1130-5, 2013

Prieto, L.; Lamarca, R. \& Casado, A. Assessment of the reliability of clinical findings: the intraclass correlation coefficient. Med. Clin. (Barc.), 110(4):1425,1998 .

Schilder, H. Cleaning and shaping the root canal. Dental Clin. North Am., 18(2):269-96, 1974.

Silva, J. M.; Brandão, G. A.; Silva, E. J. \& Zaia, A. A. Influence of working length and foraminal enlargement on foramen morphology and sealing ability. Indian J. Dent. Res., 27(1):66-72, 2016.

Vanni, J. R.; Santos, R.; Limongi, O.; Guerisoli, D. M. Z.; Capelli, A. \& Pécora, J. D. Influence of cervical preflaring on determination of apical file size in maxillary molars: SEM analysis. Braz. Dent. J., 16(3):181-6, 2005.

Vertucci, F. J. Root canal morphology and its relationship to endodontic procedures. Endod. Top., 10(1):3-29, 2005.

Wolf, T. G.; Paqué, F.; Zeller, M.; Willershausen, B. \& Briseño-Marroquín, B. Root canal morphology and configuration of 118 mandibular first molars by means of micro-computed tomography: An ex vivo study. J. Endod., 42(4):610-4, 2016

Wu, M. K.; R'oris, A.; Barkis, D. \& Wesselink, P. R. Prevalence and extent of long oval canals in the apical third. Oral Surg. Oral Med. Oral Pathol. Oral Radiol. Endod., 89(6):739-43, 2000.

Wu, Y. C.; Su, C. C.; Tsai, Y. C.; Cheng, W. C.; Chung, M. P.; Chiang, H. S.; Hsieh, C. Y.; Chung, C. H.; Shieh, Y. S. \& Huang, R. Y. Complicated root canal configuration of mandibular first premolars is correlated with the presence of the distolingual root in mandibular first molars: A cone-beam computed tomographic study in Taiwanese individuals. J. Endod., 43(7):1064$71,2017$.

Corresponding author:

Jaime Abarca

Faculty of Dentistry

Universidad San Sebastián

Lago Panguipulli 1390,

Pelluco Alto - Puerto Montt

CHILE

Email: jabarcar@docenteuss.cl

Received: 18-08-2017

Accepted: $14-11-2017$ 